\title{
Antistress Activity of Tinospora Cordifolia with Application of Yoga
}

\author{
Research Article
}

\section{Partha Biswas $^{1 *}$, Achintya Saha ${ }^{2}$, Lakshmi Narayan Maity ${ }^{3}$}

1 Lecturer, Department of Basic Principle, Institute of Post Graduate Ayurvedic Education \& Research, Cal -9

2. Associate Professor,Department of chemical Technology, University college of Science \& Technology, Cal -9

3.Lecturer, Department of Kaya Chikitsha, Institute of Post Graduate Ayurvedic Education \& Research, Cal -9

\begin{abstract}
Aim: Mental stress can lead to various biochemicals, physiological and psychological changes in human body. The present study was designed to evaluate the antistress activities of Tinospora cordifolia (wild) Miers associated with yoga

Methods: A randomized double blind placebo control 8 weeks study was conducted. The mental stress patients were diagnosed clinically by using different validated psychological rating scales. A total of 63 patients with mental stress were randomized into four groups. The antistress activities of the treatments were measured by different psychological rating scales as well as various biochemical parameters i.e. lipid profile, serum glucose concentration.

Results: The serum glucose, lipid like triglyceride, cholesterol, ldl -cholesterol and psychological parameters like anxiety, depression were significantly increases in patients with chronic mental stress. However following treatment with Tinospora cordifolia associated with practice of yoga significantly reduced various stress induced psychological and biochemical parameters $(\mathrm{P}<0.001)$

Conclusion: The findings of the clinical study suggested that Tinospora cordifolia and practice of yoga have significant anti stress activities as shown by its mitigating effects on chronic stress induced psychological and biochemical perturbation comparable to that induced by well known adaptogenic agent diazepam.
\end{abstract}

Keywords: Anti stress, Adaptogenic, Tinospora cordifolia,(wild) Miers

\section{Introduction}

Modern century is a century of stress. With continuous increment of demand and to fulfill the requirements people are facing some kind of mental stress. Clinical observation suggests that stress has significant role in 80 $\%$ of all major illness. Stress is said to be one of the largest killers of man today. Stress has been postulated to be involved in the etiopathogenesis of a wide variety of disease state like immunosuppression, endocrine disorders including diabetes mellitus, hypertension, peptic ulcer, ulcerative colitis, cancer etc. (1) Tinospora cordifolia is the most important rasayan drug has been traditionally used since ancient period. Most of the rasayan drugs have shown neuropsychological, immunomodulatory and adaptogenic activity. Yoga has been used to maintain the mental health since ancient period. Though the adaptogenic activity of Tinospora cordifolia and application of yoga in mental health is well documented but their influence on hyperlipidemia, hyperglycemia as well on oxidative stress injury is less clearly defined.

\footnotetext{
*Corresponding Author:

\section{Partha Biswas}

Lecturer, Department of Basic Principle,

Institute of Post Graduate Ayurvedic Education \& Re-

search, 294/3/1 A.P.C Road Cal -9.

E-mail-drpartha264@gmail.com
}

Being a global problem, the evaluation of potent and nontoxic drugs is a matter of concern. Thus the therapeutic measure in relation to antistress activity of Tinospora cordifolia and yoga has taken into consideration in the present study.

\section{Materials and Methods}

The study was conducted in the Department of Basic Principle, Institute of Postgraduate Ayurvedic Education \& Research Kolkata. A written informed consent was obtained from all the patients enrolled in the study.

At screening the eligibility criteria for inclusion in the study were based on history, clinical examination, age group of $16-70$ years of both gender, duration of mental stress ranging from 2-6 month and those were obtained at least total score of 20 in Distress Symptoms Scale considered for inclusion. Exclusion criteria of the study were patient suffered from psychosis, patients who were already on other medication for the treatment of chronic stress, those with hepatic, cardiac, and renal failure.

\section{Drugs and Chemicals}

For the present study the fresh plant Tinospora cordifolia was collected from the local market and properly identified by department of chemistry and 
pharmacology in Central Research Institute of Ayurved, Kolkata. It was dried at $37^{\circ} \mathrm{C}$ in an incubator. Then the dried plant were powdered in a mixer grinder and used as test drug. Diazepam (Sigma laboratories Limited) was used as a standard anti stress agent. The diagnostic reagent kits (Bayer's India ltd. Mumbai) of sugar, and lipid profile.

\section{Methods of yoga}

Pranayam ( Breathing control exercise) The exercise was done by the patients in a particular sequences viz.inspiration for two seconds, holding of breath for eight seconds and expiration for four seconds. Such exercise was carried on 20 minutes at a time with relaxation posture for 5 minutes. Dhayan - (Meditation) Patients were required a quite environment with a comfortable position (cross legged lotus posture) the sacred word (mantra to be repeated silently with eyes fully closed for 20 minutes. (2).

\section{Study Design}

The study was performed as an 8 weeks, randomized, double blind, and placebo control trial where as each subject acted as own control.

\section{Randomization}

The estimated sample size for the study (including dropouts) was 72 patients. Patients who fulfilled the inclusion / exclusion criteria were randomized by random number table into the four groups.

\section{Treatment Schedule}

Study patients randomly received either one of the following medication 1. Group $-\mathrm{A}$, treated as placebo and received rice grain powder 3 gm twice daily p.o. 2 . Group -B, patients received Diazepam at a dose of 10 mg per day, p.o. 3. Group $-\mathrm{C}$, patients received powder of Tinospora cordifolia (stem) p.o.at a dose of $3 \mathrm{gm}$ twice daily with water as a vehicle.. 4. Group -4, Patients received both powder of Tinospora cordifolia (3 gm twice daily) and yoga. All patients were followed up monthly for a period of 2 months and were assessed for efficacy.

\section{Assessment for Efficacy}

The primary efficacy parameter related to chronic stress condition was reduction of severity of mental stress in Distress Symptoms Scale. The Distress Symptoms Scale consists 50 items, each item was rated 0 to 10 score. The score was generally remaining in the following categories, high distress symptoms 50 or more, medium distress symptoms $(20-49)$ and low distress symptoms $(0-19)$ (3) The other assessment scales were State - Trait Anxiety Inventory Scale for assessment of anxiety (4) and Beck Depression Inventory Scale for assessment of Depression.(5)

The secondary efficacy parameters were different biochemical parameters i.e. serum glucose level (6) total
Cholesterol, (7) Triglyceride, (8). HDL-Cholesterol, (9), LDL-Cholesterol ( 9).

\section{Statistical Analysis}

The descriptive statistics were expressed as mean \pm s. e. From the same group pre and post treatment data were analyzed by paired $\mathrm{t}$ test. $\mathrm{P}<0.05$ was considered as significant and were done using Statistical Package for the Social Sciences (SPSS)

Figure 1. Disposition of study patients

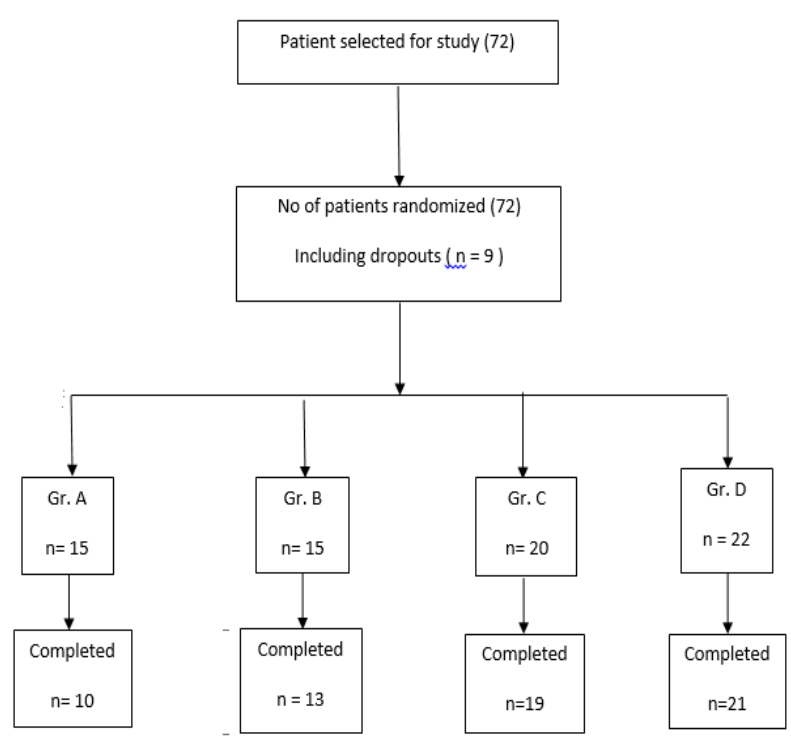

\section{Results}

Assessment of serum glucose level

Fasting serum glucose level significantly increased in almost all patients with chronic mental stress in different trial groups. Concentration of serum glucose at before and after treatment presented in Table -1. A significant reduction in serum glucose concentration was observed in group $-\mathrm{C}(\mathrm{P}<0.01)$ and group $\mathrm{D}(\mathrm{P}<0.001)$ treated with powder of Tinospora cordifolia alone and Tinospora cordifolia with yoga respectively, where as placebo did not show any significant effect on serum glucose concentration.

\section{Assessment of serum lipid}

Concentration of serum lipid at before and after treatment presented in Table -1 . There was a generalized increase the serum lipid level of Triglyceride, total Cholesterol and LD.L - cholesterol in patients with chronic stress. Serum triglyceride concentration significantly reduced in Group $-\mathrm{C}(\mathrm{P}<$ 0.01) and Group D. ( $\mathrm{P}<0.001)$. Serum cholesterol significantly reduced in group $-\mathrm{D}(\mathrm{P}<0.001)$ treated with powder of Tinospora cordifolia with yoga. Serum LDL- cholesterol significantly reduced in both group $\mathrm{C}(\mathrm{P}<0.001)$ and group $-\mathrm{D}(\mathrm{P}<0.001)$ as comparison to their own control. Serum H D L cholesterol concentration marginally elevated in Group $-\mathrm{C}(\mathrm{P}<0.05)$ and Group $-\mathrm{D}(\mathrm{P}<0.05)$ treated with 


\section{International Journal of Ayurvedic Medicine, 2015, 6(3), 220-224}

powder of Tinospora cordifoila alone and Tinospora cordifolia with yoga respectively.

\section{Assessment of different psychological rating scales}

All the four treatment groups showed a significant elevation of score of distress symptoms scale A significant score reduction was found in group $-\mathrm{B}(\mathrm{P}<$ $0.01)$, group $-\mathrm{C}(\mathrm{P}<0.01)$ and group $-\mathrm{D}(\mathrm{P}<0.01)$ treated with diazepam,Powder of Tinospora cordifolia alone and Tinospora cordifolia with yoga respectively, whereas placebo group did not show any significant changes. The score in Beck Depression Inventory Scale significantly increased in all four treatment groups in patients with chronic stress. Depression level significantly reduced in group $-\mathrm{C}(\mathrm{P}<0.01)$ and group $\mathrm{D}(\mathrm{P}<0.01)$ in comparison to their own control. The score in State and Trait Anxiety Inventory Scale significantly increased in patients of all four treatments groups. Level of anxiety significantly decreased in group $-\mathrm{D}(\mathrm{P}<0.001)$ treated with powder of Tinospora cordifolia with yoga in comparison to their own control.

Table 1. Effect of Drugs on various Biochemical parameters in patients with chronic mental stress.

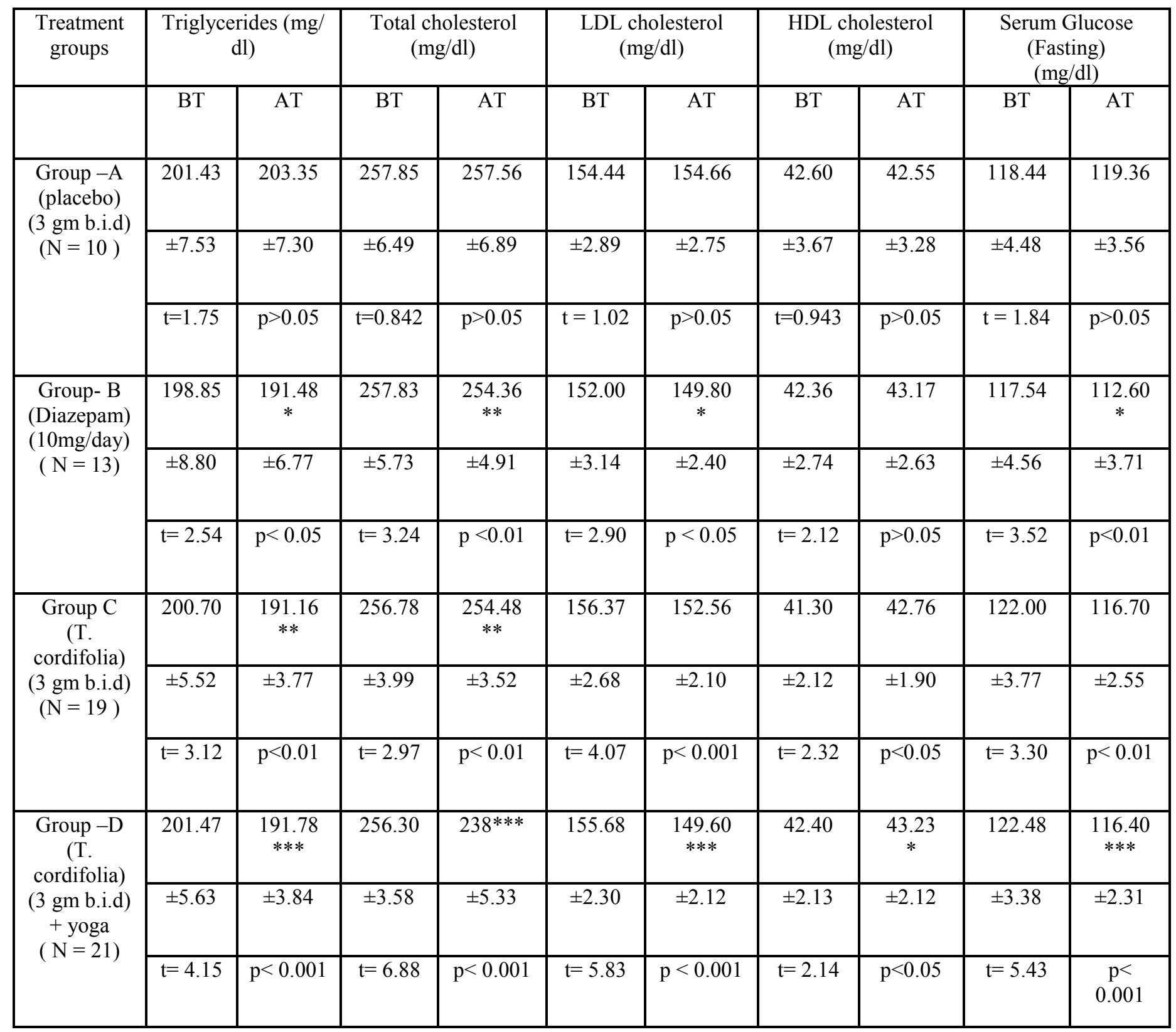

Data were expressed as mean \pm standard error, ${ }^{*}=\mathrm{P}<005$ (level of significant), $* *=\mathrm{P}<0.01$ (level of significant), $* * *=\mathrm{P}<0.001$ (level of significant) as compared to their corresponding value before treatment, $\mathrm{P}<0.05$ was considered as significant, B.T -Before treatment, A.T -After treatment,Paired t test was used to compare means and evaluate the $p$ values. 
Table 2, Effect of different drugs on various psychological parameters in patients with chronic stress

\begin{tabular}{|c|c|c|c|c|c|c|}
\hline \multirow[t]{2}{*}{ Treatment Group } & \multicolumn{2}{|c|}{$\begin{array}{c}\text { Distress Symptoms } \\
\text { Scale }\end{array}$} & \multicolumn{2}{|c|}{$\begin{array}{l}\text { Beck Depression } \\
\text { Inventory Scale }\end{array}$} & \multicolumn{2}{|c|}{$\begin{array}{l}\text { State \& Trait Anxiety } \\
\text { Inventory Scale }\end{array}$} \\
\hline & B.T & A. $T$ & B.T & A.T & B. $\mathbf{T}$ & A.T \\
\hline $\begin{array}{c}\text { Group -A ( placebo) } \\
3 \text { gm b.i.d } \\
(n=10)\end{array}$ & $\begin{array}{c}39.00 \\
\pm \\
3.18 \\
\\
\mathrm{t}=.748\end{array}$ & $\begin{array}{c}36.40 \\
\pm \\
2.83 \\
\mathrm{p}>0.05\end{array}$ & $\begin{array}{c}27.30 \\
\pm \\
2.09 \\
t=1.24\end{array}$ & $\begin{array}{c}27.40 \\
\pm \\
1.88 \\
\mathrm{p}>0.05\end{array}$ & $\begin{array}{c}59.10 \\
\pm \\
3.13 \\
\mathrm{t}=1.17\end{array}$ & $\begin{array}{c}58.70 \\
\pm \\
3.29 \\
\\
\mathrm{p}>0.05\end{array}$ \\
\hline $\begin{array}{c}\text { Group -B (Diazepam) } \\
(10 \mathrm{mg} / \text { day) } \\
(\mathrm{n}=13)\end{array}$ & $\begin{array}{c}39.76 \\
\pm \\
2.14 \\
\\
\mathrm{t}=3.67,\end{array}$ & $\begin{array}{c}36.92^{* *} \\
\pm \\
1.56 \\
\mathrm{p}<0.01\end{array}$ & $\begin{array}{r}30.76 \\
\pm \\
2.25 \\
\mathrm{t}=3.94\end{array}$ & $\begin{array}{c}27.38 * * \\
\pm \\
1.70 \\
\mathrm{p}<0.01\end{array}$ & $\begin{array}{r}60.15 \\
\pm \\
3.17 \\
\\
\mathrm{t}=3.84,\end{array}$ & $\begin{array}{c}56.30^{* *} \\
\pm \\
2.57 \\
\\
\mathrm{p}<0.01\end{array}$ \\
\hline $\begin{array}{c}\text { GroupC (T. cordifolia) } \\
(3 \text { gm b. i. d) } \\
(n=19)\end{array}$ & $\begin{array}{c}38.36 \\
\pm \\
2.14 \\
\mathrm{t}=3.27,\end{array}$ & $\begin{array}{c}35.57 * * \\
\pm \\
1.73 \\
\mathrm{p}<0.01\end{array}$ & $\begin{array}{r}29.52 \\
\pm \\
2.03 \\
\mathrm{t}=4.94\end{array}$ & $\begin{array}{c}24.10 * * * \\
\pm \\
1.58 \\
\mathrm{p}<0.001\end{array}$ & $\begin{array}{r}60.10 \\
\pm \\
2.69 \\
\mathrm{t}=3.67\end{array}$ & $\begin{array}{c}57.00^{* *} \\
\pm \\
2.02 \\
\mathrm{p}<0.01\end{array}$ \\
\hline $\begin{array}{c}\text { Group -D } \\
\text { T.cordifolia }+ \text { yoga } \\
(3 g m \text { b.i.d }) \\
(n=21)\end{array}$ & $\begin{array}{r}40.66 \\
\pm \\
1.84 \\
\\
\mathrm{t}=3.04,\end{array}$ & $\begin{array}{c}34.71 * * \\
\pm \\
1.45 \\
\mathrm{p}<0.01\end{array}$ & $\begin{array}{r}29.60 \\
\pm \\
1.59 \\
\mathrm{t}=4.13\end{array}$ & $\begin{array}{c}23.15^{* * *} \\
\pm \\
1.33 \\
\mathrm{p}<0.001\end{array}$ & $\begin{array}{c}60.47 \\
\pm \\
1.98 \\
\mathrm{t}=3.75\end{array}$ & $\begin{array}{c}54.60 * * \\
\pm \\
1.74 \\
\text { p }<0.01\end{array}$ \\
\hline
\end{tabular}

$*=\mathrm{P}<005, * *=\mathrm{P}<0.01 * * *=\mathrm{P}<0.001$ as compared to their corresponding value before treatment, $\mathrm{P}<$ 0.05 was considered as significant B.T -Before treatment, A.T -After treatment,Data were expressed as mean \pm standard error.

\section{Discussion}

The prevention and management of stress disorders a major clinical problem. Benzodiazepines appear to be effective against acute stress but to fail to prevent the consequence of chronic stress. It is well established that almost any type of physical or even mental stress can lead to greatly enhanced secretion of ACTH and consequently of cortisol as well. The regulation of glucocorticoid synthesis and release is controlled by HPA axis (10). The elevation of serum glucose concentration in patient with mental stress could be due to high level of serum cortisol concentration. Cortisol induced insulin resistance and gluconeogenesis that causes increase concentration of serum glucose level. (11) Our present study suggested that Tinospora cordifolia has a significant antihyperglycemic activity. Tinospora cordifolia is widely used in Ayurvedic medicine for treating diabetes mellitus. Effect of fasting blood sugar, glucose tolerance and against equieprine induced hyperglycemia has been studies in several preclinical studies. The aqueous and alcoholic extract reduction in fasting blood sugar which has been interpreted as indicating indirect action of drug on carbohydrate metabolism. It has been reported that the action of the drug is due to its favorable effects on the endogenous insulin secretion, glucose uptake inhibition of peripheral glucose release.(12)

Activation of sympathetic nervous system during psychological stress increases the production of serum lipids and lipoproteins by altering lipid metabolic process. Catecholamine stimulates lypolysis in adipose tissue through activation of hormone -sensitive lipase, leading to the breakdown of triglyceride into fatty acid and glycerol. This effect is sensitized by cortisol. Increased level of fatty acids and cortisol leads to insulin insensitivity in tissue and promote increased triacylglycerol synthesis by the liver. These combined effects result in increased hepatic production and secretion of very low density lipoprotein which is ultimately converted to LD L- cholesterol in blood. (13). Serum triglyceride, total cholesterol, and LDlcholesterol significantly reduced in group $-\mathrm{c}$ treated with Tinospora cordifolia (3 gm) combined with yoga. These finding suggested that that Tinospora codifolia combined with yoga has a significant anti lipidimic activities. Sarma DNK, Khora RL reported that Tinospora cordifolia has ability to reduce adrenocortical response which indicates its effect on lipid metabolism. (14).The hypolipidemic effect of an aqueous extract of Tinospora cordifolia was evaluated. Extract of Tinospora codifolia at a dose of $5.0 \mathrm{~g} / \mathrm{kg}$ body weight showed highest hypolipidemic effect. (15). 
It is well known that anxiety, depression, feeling of anger, fear, hopelessness and other emotions are often linked to stress.

The result of the Beck Depression Inventory scale indicated that chronic stress induced mild to moderate depression. $(>20)$. There is a considerable experimental and clinical evidence suggested that chronic stress induces endogenous depression. (16) Benzodiazepines have well characterized in terms of their anxiolytic and hypnotic action via activation of GABAergic neurons.

Dhyan or meditation is one of the most important components of Patanjali's integrated practice of yoga. Udupa et al. reported that dhyan of vipasan style in a series of Indian and foreign volunteers have shown significant biochemical changes in blood, neurohormonal activity and conforming electrophysiological changes.

Increased generation of oxidative free radicals or impaired antioxidant defense mechanism have been implicated in chronic stress induced perturbed homeostasis including inflammation, diabetes mellitus and other stress related disorders. (17). Plants containing flavonoid and phenolic compound are known to possess strong antioxidant properties.(18). It was observed from several experimental studies that Tinospora cordifolia has a significant antioxidant property. Thus the observed adaptogenic antistress effects of Tinospora cordifolia may be at least partly due to its antioxidant property.

\section{Conclusion}

In conclusion, the present findings demonstrate that stress is the arousal of body, mind and behavior in response to demand made by different kind of stressors. The relationship between mental stress and blood glucose level was considerably stronger, while serum lipid concentration was only weakly associated with mental stress.

A strong correlation between mental phenomena like anxiety, depression and mental stress was found in the present study.

The findings of the present study suggested that Tinospora cordifolia and practice of yoga has a significant anti stress adaptogenic activity as shown by its mitigating effects on several chronic stress induced biochemical and behavioral perturbations, comparable to that induced by well known adaptogenic agent diazepam.

\section{Acknowledgements}

We are extremely thankful to Dr. P.K.Mukherjee, Project officer, I.P.G. A E.\& R at SVSP Hospital, Kolkata for allowing us to do the research work.

\section{References}

1. Elliot G. R, EisdorferC. Stress and Human health, New York. Springer Publication Co. (1982).

2. Udapa K.N. Stress and its management by Yoga; Motilal Banarasidass 1985, P- 163.

3. Schafer W. Stress Management for Wellness, Thomson ; (2004), $4^{\text {th }}$ edition P -136.

4. Spielberger C D, Gorsuch RL, Lushene RE. STAI,Manual for State Trait Anxiety Inventory. ; Palo Alto 1970.

5. Achieves of General Psychiatry,1961 : 4; p-561.

6. Tieiz N W. In Clinical Guide to Laboratory Text ;W.B Sauders Co. Philadelphia, 1976: P- 238.

7. Trinder P. Ann Clinical Biochem; 1969, 6: p-24.

8. Werner M, Gabrielson D G, Eastman G, Clinical Chem; 1981, 27: p-268.

9. Frieddewald W T et al Clin Chem 1972; 18: 499.

10. Palkovits M Prog, Brain Research: 1987; 72, : p47-55.

11. Arther C. Guyton; Text Book of Medical Physiology, $7^{\text {th }}$ Edition; London ; Philadelphia,: 1986, P-914.

12. http://www.gorkhaexim.com/tea/gurjop.htm, [George et al, J Sci Industr Res, 6(B) (1947) 42].

13. Brindlev DN, Mc Cann BS, Niaura R, Stoney CM, Suarez Ec. Stress and Lipoprotein metabolism: modulators and mechanism: Metabolism 1993; 42: p-3-15.

14. Sarma DNK, Khosa RL, Ghansauria JNP and Sahai M. Antistress activity of T.cordifolia and C. asiatica extract. Phytotherapy Research.1996: 9; p589-596

15. Prince P., MenonVP, Hypolipidemic action of T. cordifolia root in alloxan induced diabetic rats. J. Ethnopharmacology ; 1999 : 64 (1): p- 53.

16. Weiss JM, Glazer H.i. Coping behavior and stress induce behavioral depression: studies of the role of brain catecholamine; in the psychobiology of depressive disorders; Implication for the effect of stress. New York, Academic press, 1979; p-125.

17. Maxwell Srj. Prospects for the use of antioxidants therapies. Dug; 1995: 21, p - 474-484.

18. Tripathi YB,Chaurasia S, Tripathy E, Indian J. Exp Biol; 1996: 34; p-523-526. 